\title{
Diffuse unilateral subacute neuroretinitis: review article
}

\author{
Thiago José Muniz Machado Mazzeo ${ }^{1 *} \mathbb{D}$, Mario Martins dos Santos Motta ${ }^{2}$ and André Luiz Land Curi ${ }^{3}$
}

\begin{abstract}
Diffuse unilateral subacute neuroretinitis (DUSN) is an ocular infectious disease that can lead to severe visual impairment and blindness. It usually occurs in healthy young individuals and depending on the stage of the disease, it may present as vitritis, multifocal gray-white lesions in the outer retina, and derangement of the retinal pigment epithelium, narrowing of the retinal vessels and optic atrophy. Parasites of different sizes and species have been proposed as the etiologic agent of DUSN, including Ancylostoma caninum, Toxocara canis, and others. Thus, it is hypothesized that different infectious worms may be considered as the likely cause of both an autoimmune and toxic form of nematode retinopathy. Because serologic testing is variable, the definitive diagnosis is made when clinical characteristics of DUSN are found in conjunction with an intraocular worm. Ancillary tests can assist in the differential diagnosis when the nematode cannot be visualized, such as fluorescein and indocyanine green angiography, electrophysiological tests, visual field studies, and more recently, optical coherence tomography angiography. Cases in which the worm can be identified, it is defined as confirmed DUSN, and eyes with the typical clinical features but without identification of the worm should be classified as presumed DUSN. In confirmed DUSN, the classic treatment is directly photocoagulation of the worm; however, it can only be visualized in 30\% (to 40\%) of cases. Treatment of presumed DUSN cases with high-dose oral albendazole has shown encouraging results. However, perhaps due to the disease's rarity or its underdiagnosis, there are no studies comparing current treatment modalities in both presumed and confirmed DUSN. Due to the possibility of this disease being, in part, autoimmune nematode retinopathy, corticosteroids associated with both albendazole or laser therapy, could be in any way beneficial. Thus, further comparative studies are necessary to elucidate the best treatment for this potentially blinding disease.
\end{abstract}

Keywords: Eye infections, Uveitis, Choroiditis, Retinitis, Albendazole, Photocoagulation

\section{Background}

The objective of this article is to do a prospective literature review, describing the manifestations and etiology of DUSN, as well as its pathogenesis, diagnosis, and current types of management. The treatment is discussed according to the point of view of various authors, since, to the best of our knowledge, there is no consensus about the best treatment plan for both confirmed and presumed DUSN, which ranges from oral antihelmintic (albendazole), corticosteroids, to worm photocoagulation.

\footnotetext{
* Correspondence: mazzeothiago@yahoo.com

'Ophthalmology Residency Program, Federal University of the State of Rio de Janeiro (UNIRIO), Gaffrée and Guinle University Hospital, Rio de Janeiro, Brazil

Full list of author information is available at the end of the article
}

\section{Introduction}

Diffuse unilateral subacute neuroretintitis (DUSN) is an ocular infectious disease that can lead to visual impairment and blindness. It was first described by Gass in 1978 [1], in which healthy young individuals presented with insidious, usually severe unilateral visual loss, vitritis, diffuse, and focal pigment epithelial derangement in the earlier stages of the disease. If left untreated and the inflammation persists, the disease can lead to narrowing of the retinal vessels and optic atrophy, causing permanent vision loss. Despite DUSN being mostly described as unilateral disease, rare bilateral cases are reported in the literature [1-6].

A worm, whose etiology has not been completely elucidated, is thought to be responsible for this inflammatory and degenerative process in neurosensory retina 
and retinal pigment epithelium (RPE). Infection of the eye by a nematode was first reported in the year 1950 by Wilder [7] in enucleated eye specimens, and Parsons [8] provided the first report of a subretinal mobile worm causing an ocular syndrome in 1952. One of the first reported Brazil cases was described in 199 [9-14].

The subretinal worm is found in less than half of the cases, and most patients are under 20 years of age with already severe visual impairment, due to presenting in the later stages of the disease, where the likelihood of improvement is low, despite therapy. In cases of early diagnosis, prompt treatment, whether with oral antihelminthic or direct photocoagulation of the worm, patients may show good visual improvement and have a more favorable prognosis [3, 15-18].

The objective of this article is to describe the manifestations and etiology of DUSN, as well as its pathogenesis, diagnosis, and current types of management.

\section{Etiology and epidemiology}

Parasites of different sizes and several species of nematodes have been proposed as the etiologic agent of DUSN, including Toxocara canis, Baylisascaris procyonis, Ancylostoma caninum, and others. B. procyonis and A. caninum are thought to be the most common infectious agents, but despite many efforts, no conclusion has been reached about the specific organism causing this disease. Precise diagnosis of these nematodes is also limited due to the lack of good serologic testing or stool examinations, and most reports are made based on clinical exam. Thus, the majority of the studies argue that different agents may be considered as the likely cause of the same entity, called DUSN $[1,3,6,15,19,20]$.

Since DUSN is thought to be an ocular final common result of different infectious microorganisms, the mode of transmission will vary accordingly. In regions from the southeastern of the USA and South America, the nematode may vary in length from approximately 400 to $700 \mu \mathrm{m}$. In other areas, such as the north Midwestern USA, it measures approximately 1500 to $2000 \mu \mathrm{m}$ in length. Moraes et al. reported the first South American case of DUSN caused by the larger nematode $[3,6,21]$.

Previous reports tried to identify the nematode, even through the retinal biopsy (transscleral approach); however, due to poor histologic details, precise identification of the nematode was not possible. Agent identification in the majority of studies is based on a combination of measuring the parasite, serologic testing, and epidemiological data, all of which have limited accuracy $[5,9,22]$.

Oréfice et al. [23] found a $47.62 \%$ positivity for enzyme-linked immunosorbent assay (ELISA) in a case series of 23 DUSN patients, and in 2 with the live nematode, the ELISA was negative. Other studies observed that ELISA anti-T. canis was negative in most of the 39 DUSN cases he studied [19].

\section{T. canis}

Gass and Olsen [9] previously suggested that T. canis was not the causative microorganism due to the lack of serologic evidence. In addition, the clinical picture was unlike that associated with ocular toxocariasis, but Oppenheim et al. reported a case of Toxocara DUSN in which the patient's positive ELISA titer decreased fourfold over a 2-year period. This suggests that the serologic variability may be a reflection of the timing of the serology in relation to the onset of the disease or the immune status of the patient [24].

\section{B. procyonis}

Significant morphometric, serologic, and epidemiologic support for Baylisascaris as the causative agent of DUSN in northern climates was published by Goldberg et al. [25]. It is described to be a large nematode (ranging from 400 to $2000 \mu \mathrm{m}$ ) found in raccoons and may cause not only DUSN in patients, when infectious eggs from feces are ingested, but also visceral-ocular larva migrans and eosinophilic meningoencephalitis. Even though most patients have no history of exposure to raccoons, large nematode DUSN patients are seen to be from areas of the USA where raccoons are not only common but also infected with B. procyonis $[5,12,26]$.

\section{A. caninum}

It is a common cause of dog parasitic infection in South America that cause cutaneous larva migrans (CLM) in humans when infectious eggs from dog feces are ingested or when the larvae enter through the skin (usually the foot). It is also a frequent cause of CLM in the southeastern USA, and occasionally, it may precede the onset of DUSN $[1,3,17]$.

It is described to be one of the small nematodes (approximately $650 \mu \mathrm{m}$ ) that cause the syndrome. The infective larva of $A$. caninum is capable of surviving in host tissue, for months and probably years without changing size or shape. No serologic test is currently available for Ancylostoma [9, 27].

\section{Pathophysiology}

The pathogenesis of DUSN may be related to the presence of a larva in subretinal space, promoting an extensive inflammatory and degenerative process of both the retina and retinal pigment epithelium (RPE). Infiltration of eosinophils, macrophages aggregates, and gliosis may affect all retinal layers, leading to variable loss of ganglion cells. Toxic products released by the larva in the subretinal space would locally affect the external portion of the retina, and a diffuse tissue reaction would lead to 
external and internal retinal damage. Vascular narrowing and progressive ganglion cell loss occur until optic atrophy establishes [9].

So that, the association of worm's migration through the neurosensorial retina, the toxicity of its excretions and the host immunological response are thought to be the main pathophysiological mechanisms, converging into a toxic autoimmune nematode retinopathy $[3,28]$.

\section{Clinical characteristics}

DUSN is most frequently seen in healthy children or young adults with no significant past ocular history. The clinical findings depend on the stage of the disease, where it can be described as early or late and can vary from evanescent multifocal white-yellowish lesions at the level of the outer retina and choroid, to narrowing of the retinal vessels and optic atrophy [3, 9, 29].

\section{Early stage}

In the acute phase of the disease, patients usually present visual loss that is often related to vitritis and optic disc edema. Evanescent multifocal gray-white lesions (Fig. 1) at the level of the outer retina, which typically cluster in one segment of the fundus, can also be visualized. These lesions are thought to be related to possible reactions to the nematode in subretinal space and characteristically migrate and change according to worm's location. It may or may not leave a residual retinal lesion depending on the degree of host immune response against the toxic products of the worm [20, 3032].

As the worm moves to another part of the retina, the lesions fade, explaining the evanescent aspect of these gray-white lesions and its reappearance in a different place, whether in the vicinity of the previous ones or not. Visual loss is rarely reversible and is usually worse than 20/200 in approximately half of the patients. Central or paracentral scotomas in the visual field may also be present $[1,20]$.

In approximately 25 to $40 \%$ of cases, a worm is visualized during the eye examination.

The intraocular worm is seen as a motile, white nematode that varies in length from 400 to $2000 \mu \mathrm{m}$. Some worm species are more photosensitive than others, so that, examining light from slit lamp may cause the worm to move, a behavior which may be especially useful in cases of worms located in the macula, stimulating them to move away to an area where photocoagulation of the worm can be safely performed [29, 31, 33, 34].

Gass and Braunstein [20] reported that there is a greater likelihood of the longer worm leaving a tract of coarse clumping of RPE in the wake of its travels,

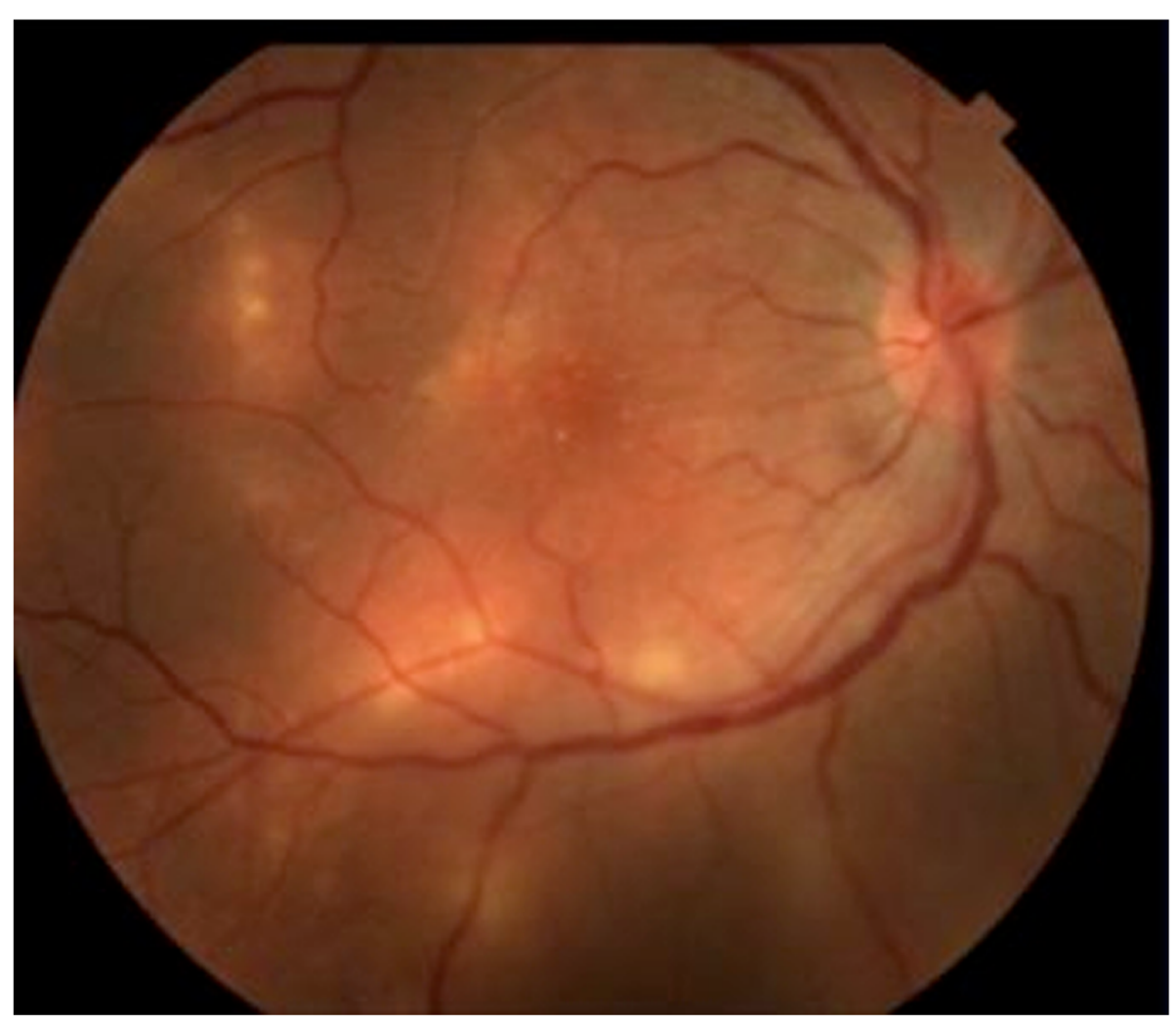

Fig. 1 Multifocal gray-white lesions in the right eye of a presumed DUSN patient. 
whereas the shorter worm tends to leave focal, chorioretinal atrophic scars. The focal pigment epithelial changes are related to the travel pattern of the worm, while focal chorioretinal white spots are induced by an immune response to secretion or excretion from the worm. Diffuse pigment epithelial changes are suggested by some authors, to be related to a toxic reaction. Less frequent findings include iridocyclitis, subretinal hemorrhages, perivenous exudation, macular cysts, local retinal detachments, and subretinal neovascularization $[1,5$, $16]$.

\section{Late stage}

In the later stages of the disease, the patient may present mild vitritis, evidence of tunnels by optical coherence tomography (OCT) in the subretinal space (Garcia's sign), focal, and diffuse degenerative changes in the RPE and retina. Vascular narrowing and progressive ganglion cell loss occur until the optic disc becomes atrophic (Fig. 2 ), leading to permanent vision loss [2, 3, 31, 35].

Retinal arteriole narrowing may vary by quadrant, and in conjunction with optic atrophy, it usually accompanies progressive changes in the RPE. According to some authors, toxic products released by the larva in the subretinal space would locally affect the external portion of the retina, whereas a more diffuse tissue reaction would damage all retinal layers $[2-4,9,28,30]$.
Visual acuity can be profoundly impaired, with $80 \%$ or more of the patients showing 20/200 or worse. Over weeks or months, diffuse and focal depigmentation of the RPE occurs, usually most prominent in the peripapillary and peripheral retina and less prominent in the central macular area $[15,16,31,36]$.

\section{Ancillary testing}

\section{Fluorescein angiography}

There is hypofluorescence of the focal gray-white lesions of active retinitis followed by staining, in the early stage of FA. Dye leakage can be observed from the capillaries on the optic disc, and occasionally, in a perivenous pattern. In the later stages of the disease, FA shows considerable pigment loss from the RPE, manifesting as an irregular increase in the background choroidal fluorescence, characterizing a "window defect" [9].

\section{Indocyanine green angiography}

The choroid also seems to be involved in early-stage DUSN. Hypofluorescent dark spots seen in the affected eye are probably due to choroidal infiltration, which prevents normal indocyanine green angiography (ICG-A) impregnation. These dark spots, present in the initial ICG angiography phase, seem to either disappear or persist in the late phase of the examination. Hypofluorescent dots persisting in the late phase are interpreted as

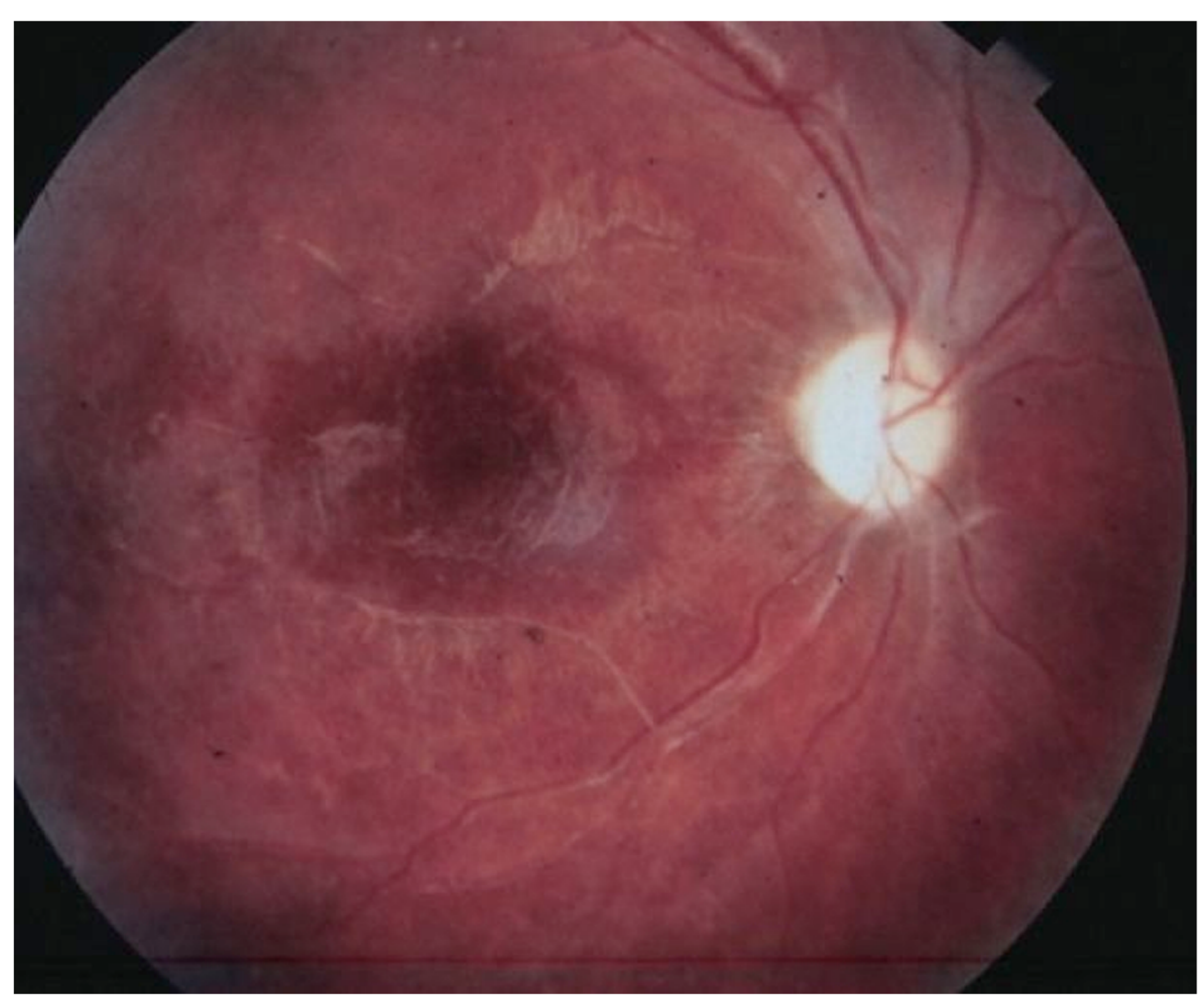

Fig. 2 In the later stage of DUSN, patient fundus presented with a pale optic disc, narrowed retinal vessels, and pigmentary alterations 
full-thickness lesions allowing no ICG diffusion, whereas dots becoming isofluorescent through the exam phases are interpreted as partial-thickness lesions progressively surrounded by the dye of adjacent tissues [37].

\section{Electroretinogram and electro-oculogram}

DUSN may present a negative electroretinogram (ERG), which can also be found in ischemic retinal diseases, indicating significant dysfunction affecting the inner retina. This characteristically pattern shows a flat and below the normal response of $B$ wave and a decrease in relation to B/A waves. Electroretinographic changes also include a mild to moderate decrease in rod and cone function, in which the $\mathrm{B}$ wave is usually more affected than the $\mathrm{A}$ wave $[3,30]$.

The mechanism of this finding can be explained as being a consequence of a possible autoimmune, inflammatory, and/or toxic aggression toward retinal bipolar cells. The ERG in the affected eye is usually abnormal even in the early in the course of the disease. About $50 \%$ of these patients can have a normal electro-oculogram (EOG), and the finding of normal EOG and abnormal ERG suggests a neuroepithelium disease. It is important that the ERG is rarely extinguished completely, which differentiates it from some tapeto-retinal degeneration $[19,35,38]$.

Multifocal ERG findings before laser treatment showed decreased foveal response density and increased parafoveal and perifoveal waveform amplitudes. Two months after the laser photocoagulation of a subretinal nematode, multifocal ERG showed full recovery and visual acuity remained 20/20 [39].

\section{Visual field studies}

Visual fields show different lesion patterns that cannot be correlated with the findings of the ocular fundus changes. However, Goldmann perimetry is useful to evaluate the remaining visual field before and after disease's treatment [18, 34, 40].

In DUSN, visual field improvement following photocoagulation of the worm has been described, but the exact mechanism is not yet fully understood. It is hypothesized that the toxic inflammatory reaction induced by the worm is reduced over the retinal pigment epithelium and adjacent tissues, after nematode eradication [4, $20,27,33,41,42]$.

\section{Optical coherence tomography}

Optical coherence tomography (OCT) can be important for the characterization of the clinical picture of DUSN, given that the worm cannot always be found, and therefore, it may help to identify the disease, assisting in the differential diagnosis and also monitor treatment's anatomical response [30, 43].
OCT common findings are neuroretinal atrophy, focal hyper-reflectivity through the retina in areas affected by the worm, and general loss of the inner retinal layer. However, progressive changes can range from the retinal nerve fiber layer (RNFL) to the RPE, since the worm and its toxic effects can affect all retinal layers, not only the subretinal space as it was first described [14, 30, 36].

Studies observed that there was no significant difference between the RNFL thickness in patients with or without a live worm. Despite this, it is possible to have both increase (due to transitory edema) and decrease (secondary to nerve fiber loss) of RNFL thickness, as the disease progresses. In addition, decreased RNFL thickness has been previously correlated with worse visual acuity $[35,44]$.

\section{Optical coherence tomography angiography}

Gass initially described that high-quality color fundus photos were the best way to identify nematodes. However, with the worm not been found in over $50 \%$ of suspected DUSN cases, there is still significant room for other techniques. Studies demonstrated that optical coherence tomography angiography (OCT-A) is another imaging modality that can assist in the diagnose. The nematode can be detected as long as it moves because nematodes have no vascular system. However, it is possible that an inactive worm may not be detected $[1,45]$.

\section{Diagnosis}

When a worm is identified within the eye of an otherwise healthy person, unless there is peripheral eosinophilia, no further evaluation seems warranted to make the diagnosis. The nematode can be visualized in both acute and chronic phases of the disease, and in cases in which it can be identified, it should be defined as confirmed DUSN, and eyes with the typical clinical features but without identification of the worm should be classified as presumed DUSN. De Amorim Garcia Filho et al. described in a large series of 121 patients that the subretinal word could only be identified in approximately $40 \%$ of the patients $[6,16]$.

So that, despite DUSN being sometimes difficult to diagnose, especially in early stages and when the worm cannot be visualized, it should always be suspected in healthy patients with unilateral insidious vision loss, retinal vasculitis, multifocal lesions involving deep retinal layers, narrowing of the retinal vessels, or optic atrophy. The ancillary tests can both assist in the differential diagnosis and monitor the disease's progression [17, 41].

\section{Differential diagnosis}

In earlier stages of the disease, DUSN is often mistaken for other entities, including toxoplasmosis, toxocariasis, histoplasmosis, multifocal choroiditis, serpiginous 
choroiditis, acute posterior multifocal placoid pigment epitheliopathy, multiple evanescent white dot syndrome, and optic neuritis [17]

In later stages, it is important to exclude posttraumatic chorioretinopathy, unilateral retinitis pigmentosa, occlusive vascular disease, sarcoidosis, syphilis, and other toxic retinopathies $[9,32]$.

\section{Treatment}

\section{Laser treatment}

Classically, laser photocoagulation is the only recommended treatment for DUSN once the causal nematode has been located; however, searching and photocoagulation of the worm can be a very laborious and timeconsuming task, requiring a great deal of experience. Despite this, laser treatment seems to offer a good chance for halting worm's movement, decreasing intraocular inflammation and toxic damage to eye tissues. For this reason, some improvement in vision and visual field may occur after laser treatment of the worm; however, in late stages of the disease, laser treatment may not be so effective [21, 27, 34, 40,46].

In some patients where the worm is close to the macula and heavy photocoagulation may damage the fovea, it may be possible to use low level illumination or light applications of the laser to chase the worm into the mid periphery, due to its photosensitivity, where it may be destroyed with less risk of compromising patient's central vision. In addition, laser treatment should be performed as soon as the worm is identified, because they are motile and may be difficult to locate it if the procedure is delayed. Clinical treatment is limited to cases in which no worm is found despite repeated examinations $[19,34,47,48]$.

\section{Oral treatment}

The search for an oral treatment for DUSN started in 1980 with Gass and associates. After several trials with oral antihelmintic drugs, such as thiabendazole and diethylcarbamazine, it was found that the tested drugs would only destroy the subretinal worms in some of their patients. Thereby, it was hypothesized that these antihelmintic drugs would depend on an inflamed eye (blood-retinal barrier breakdown), justifying the variable efficacy [20, 49-52].

In such a way, thiabendazole and corticosteroids only demonstrated efficacy in cases where the worm cannot be found and with a moderate degree of vitreous inflammation, indicating a breakdown in the blood-retinal barrier (BRB). In this same group of patients, Gass and Olsen previously proposed the use of moderately intense scatter photocoagulation in the vicinity of the white lesions to induce the breakdown of the BRB before the administration of thiabendazole, in order to maximize its efficacy $[18,53]$.

Later on, in the search for a more effective drug for DUSN capable of crossing an intact blood-retinal barrier, experiments were done with oral albendazole, since it is an effective broad-spectrum antihelmintic drug capable of crossing the intact blood-brain barrier and has not been associated with marked systemic side effects. It acts by binding to parasite beta-tubulin, inhibiting its polymerization and impairing glucose uptake. Singledose albendazole $(400 \mathrm{mg}$ ) is believed to achieve cure rates of 90\% against Enterobius vermicularis, Ascaris lumbricoides, hookworm, cutaneous larva migrans, and giardiasis [42, 46, 54, 55].

Souza et al. reported the drug efficacy in the first case resulting in a dramatic visual improvement from counting fingers to $20 / 30$ after 1 month of treatment. In the same report, he also described 12 Brazilian patients who had significant improvement of visual acuity, visual field, and ocular inflammation after exclusive treatment with high-dose oral albendazole $(400 \mathrm{mg} / \mathrm{d})$ for 30 days. During the first weeks of treatment, it was observed worm inactivation in four patients in whom the worms were visible and no adverse drug side effects were related [18].

The optimal dosing and duration of treatment for DUSN with albendazole have still not been determined, but the suggestion to use it for 30 consecutive days was based on the good results observed in patients with neurocysticercosis. The oral absorption is low and needs to be enhanced by fatty meals. Side effects are reported as being few and mild, such as gastrointestinal upset, dizziness, rash, and alopecia. Improvements in central visual acuity (at least two lines of Snellen) and visual field (central scotoma reduction and peripheral field enlargement) were registered in the majority of patients $[4,22,33,42$, $46,54,55]$.

\section{Conclusion}

Regardless of the nature of the causative organism, and if it the nematode can be visualized or not, DUSN should always be suspected in healthy patients with unilateral insidious loss of vision, vitreous inflammation, retinal vasculitis, multifocal lesions involving deep retinal layers, narrowing of the retinal vessels, or optic atrophy.

Laser photocoagulation offers the best chance for clinical resolution of the disease, but the worm is visualized in only a small portion of the cases, in which other treatments such as high-dose albendazole have been used with efficacy and safety; however, the optimal treatments' dose and duration has still not been determined. Despite this, it is very important to establish the diagnosis in the early phase when worm photocoagulation or 
oral antihelmintic has the greatest likelihood of vision improvement.

In the literature, there are no studies comparing treatment's regimen in both presumed and confirmed DUSN. Due to the possibility of this disease having an immunological element, corticosteroids associated with both high-dose albendazole and laser therapy could be in any way beneficial. Thus, further studies are necessary to better elucidate the efficacy of current treatment modalities and its associations depending on the stage of this potentially blinding disease.

\begin{abstract}
Abbreviations
DUSN: Diffuse unilateral subacute neuroretinitis; RPE: Retinal pigment epithelium; OCT: Optical coherence tomography; FA: Fluorescein angiography; ERG: Electroretinogram; ELISA: Enzyme-linked immunosorbent assay; ICG-A: Indocyanine green angiography; EOG: Electro-oculogram; RNFL: Retinal nerve fiber layer; OCT-A: Optical coherence tomography angiography; BRB: Blood-retinal barrier
\end{abstract}

\section{Acknowledgements}

Not applicable

\section{Authors' contribution}

MTJMM was responsible for the data collection, analysis, and interpretation. MM critically revised the article, interpreted the data collected, and approved the final version for the article to be published. CA was responsible for the conception and design of the work, data analysis and interpretation, drafting, and critically revising the article. Approved the final version to be published. All authors read and approved the final manuscript

\section{Funding}

The author(s) received no financial support for the authorship and/or publication of this article.

\section{Availability of data and materials}

presented in the main paper (references) or additional supporting files

\section{Ethics approval and consent to participate}

Not applicable

\section{Consent for publication}

Not applicable

\section{Competing interests}

The authors declare that they have no competing interest

\section{Author details}

${ }^{1}$ Ophthalmology Residency Program, Federal University of the State of Rio de Janeiro (UNIRIO), Gaffrée and Guinle University Hospital, Rio de Janeiro, Brazil. ${ }^{2}$ Ophthalmology Department, Federal University of the State of Rio de Janeiro (UNIRIO), Gaffrée and Guinle University Hospital, Rio de Janeiro, Brazil. ${ }^{3}$ Research Laboratory of Infectious Diseases in Ophthalmology, National Institute of Infectious Diseases, Oswaldo Cruz Foundation, Rio de Janeiro, Brazil.

Received: 19 July 2019 Accepted: 26 November 2019

Published online: 27 December 2019

\section{References}

1. Gass JD, Scelfo R (1978) Diffuse unilateral subacute neuroretinitis. Journal of the Royal Society of Medicine. 71(2):95-111

2. Barney NP (2002) Diffuse unilateral subacute neuroretinitis. In: Foster CS, Vitale AT (eds) Diagnosis and treatment of uveitis, 1st edn. W.B. Saunders, Philadelphia, pp 475-479

3. Arevalo JF, Arevalo FA, Garcia RA, de Amorim Garcia Filho CA, de Amorim Garcia CA (2013) Diffuse unilateral subacute neuroretinitis. Journal of pediatric ophthalmology and strabismus. 50(4):204-212
4. de Souza EC, Abujamra S, Nakashima Y, Gass JD. Diffuse bilateral subacute neuroretinitis: first patient with documented nematodes in both eyes. Archives of ophthalmology (Chicago, III : 1960). 1999;117(10):1349-1351.

5. Mets MB, Noble AG, Basti S, Gavin P, Davis AT, Shulman ST et al (2003) Eye findings of diffuse unilateral subacute neuroretinitis and multiple choroidal infiltrates associated with neural larva migrans due to Bbaylisascaris procyonis. American journal of ophthalmology. 135(6):888-890

6. Sabrosa NA, de Souza EC (2001) Nematode infections of the eye: toxocariasis and diffuse unilateral subacute neuroretinitis. Current opinion in ophthalmology. 12(6):450-454

7. Wilder HC (1950) Nematode endophthalmitis. Trans Am Acad Ophthalmol Otolaryngol 55:99-109

8. Parsons HE (1952) Nematode chorioretinitis; report of a case, with photographs of a viable worm. AMA archives of ophthalmology. 47(6):799800

9. Gass JDM, Olsen KR (2001) Diffuse unilateral subacute neuroretinitis. In: Ryan SJ, Schachat AP (eds) Retina, 3rd edn. Mosby, St. Louis, MO, pp 1669-1678

10. Oliveira AA, Oréfice F (1991) Estudo de sete casos de neuroretinite difusa subaguda unilateral. Rev Bras Oftalmol. 51(1):51-55

11. Kazacos KR, Raymond LA, Kazacos EA, Vestre WA (1985) The raccoon ascarid. A probable cause of human ocular larva migrans. Ophthalmology. 92(12): 1735-1744

12. Kazacos KR, Vestre WA, Kazacos EA, Raymond LA. Diffuse unilateral subacute neuroretinitis syndrome: probable cause. Archives of ophthalmology (Chicago, III : 1960). 1984;102(7):967-968.

13. Kuchle M, Knorr HL, Medenblik-Frysch S, Weber A, Bauer C, Naumann GO (1993) Diffuse unilateral subacute neuroretinitis syndrome in a German most likely caused by the raccoon roundworm, Baylisascaris procyonis. Graefes Arch Clin Exp Ophthalmol 231(1):48-51

14. Tarantola RM, Elkins KA, Kay CN, Folk JC. Photoreceptor recovery following laser photocoagulation and albendazole in diffuse unilateral subacute neuroretinitis. Archives of ophthalmology (Chicago, III : 1960). 2011;129(5): 669-671.

15. Audo I, Webster AR, Bird AC, Holder GE, Kidd MN (2006) Progressive retinal dysfunction in diffuse unilateral subacute neuroretinitis. The British journal of ophthalmology. 90(6):793-794

16. de Amorim Garcia Filho CA, Gomes AH, de Amorim Garcia Soares AC, de Amorim Garcia CA (2012) Clinical features of 121 patients with diffuse unilateral subacute neuroretinitis. American journal of ophthalmology. 153(4):743-9

17. Rosa AA (2013) Rodrigues Neto Tdos S. [Diffuse unilateral subacute neuroretinitis (DUSN): current update]. Arquivos brasileiros de oftalmologia. 76(4):256-260

18. Souza EC, Casella AM, Nakashima Y, Monteiro ML (2005) Clinical features and outcomes of patients with diffuse unilateral subacute neuroretinitis treated with oral albendazole. American journal of ophthalmology. 140(3): $437-445$

19. Garcia CA, Sabrosa NA, Gomes AB, Segundo Pde S, Garcia Filho CA, Sabrosa AS (2008) Diffuse unilateral subacute neuroretinitis--DUSN. International ophthalmology clinics. 48(3):119-129

20. Gass JD, Braunstein RA. Further observations concerning the diffuse unilateral subacute neuroretinitis syndrome. Archives of ophthalmology (Chicago, III : 1960). 1983;101(11):1689-1697.

21. Moraes $L R$, Cialdini AP, Avila MP, Elsner AE. Identifying live nematodes in diffuse unilateral subacute neuroretinitis by using the scanning laser ophthalmoscope. Archives of ophthalmology (Chicago, III : 1960). 2002; 120(2):135-138.

22. de Souza EC, Nakashima Y (1995) Diffuse unilateral subacute neuroretinitis. Report of transvitreal surgical removal of a subretinal nematode. Ophthalmology. 102(8):1183-1186

23. Oréfice F, Gonçalves ER, Siqueira RC et al (1994) Estudo de 21 casos de Neuroretinite subaguda unilateral difusa (DUSN)-dois casos de larva móvel sub-retiniana. Ver Bras Oftalmol. 53:467-489

24. Oppenheim S, Rogell G, Peyser R (1985) Diffuse unilateral subacute neuroretinitis. Annals of ophthalmology. 17(6):336-338

25. Goldberg MA, Kazacos KR, Boyce WM, Ai E, Katz B (1993) Diffuse unilateral subacute neuroretinitis. Morphometric, serologic, and epidemiologic support for Baylisascaris as a causative agent. Ophthalmology. 100(11):16951701

26. Kazacos KR, Boyce WM (1989) Baylisascaris larva migrans. Journal of the American Veterinary Medical Association. 195(7):894-903 
27. Gass JDM (1997) Diffuse unilateral subacute neuroretinitis. In: Gass JDM (ed) Stereoscopic atlas of macular diseases: diagnosis and treatment, 4th edn. Mosby-Year Book Inc, St. Louis, pp 622-628

28. Oréfice F, Bonfi Oli AA, FRL P (1998) Diffuse unilateral subacute neuroretinitis. In. In: Oréfice F (ed) Uveitis: Clinical and Surgical. Cultura Médica, Rio de Janeiro, Brazil, pp 733-756

29. Carney MD, Combs UL (1991) Diffuse unilateral subacute neuroretinitis. The British journal of ophthalmology. 75(10):633-635

30. Berbel RF, Casella AM, de Souza EC, Farah ME (2014) Evaluation of patients with diffuse unilateral subacute neuroretinitis by spectral domain optical coherence tomography with enhanced depth imaging. Clinical ophthalmology. 8:1081-1087

31. Cortez RT, Ramirez G, Collet L, Giuliari GP (2011) Ocular parasitic diseases: a review on toxocariasis and diffuse unilateral subacute neuroretinitis. Journal of pediatric ophthalmology and strabismus. 48(4):204-212

32. Relhan N, Pathengay A, Raval V, Nayak S, Choudhury H, Flynn HW Jr (2015) Clinical experience in treatment of diffuse unilateral subretinal neuroretinitis. Clinical ophthalmology. 9:1799-1805

33. de Souza EC, da Cunha SL, Gass JD. Diffuse unilateral subacute neuroretinitis in South America. Archives of ophthalmology (Chicago, III : 1960). 1992; 110(9):1261-1263.

34. Garcia CA, Gomes AH, Garcia Filho CA, Vianna RN (2004) Early-stage diffuse unilateral subacute neuroretinitis: improvement of vision after photocoagulation of the worm. Eye. 18(6):624-627

35. Garcia CA, de Oliveira AG, de Lima CE, Rocha FN, Garcia Filho CA (2006) Retinal nerve fiber layer analysis using GDx in 49 patients with chronic phase DUSN. Arquivos brasileiros de oftalmologia. 69(5):631-635

36. Casella AM, Farah ME, Souza EC, Belfort R Jr, Oguido AP (2010) Retinal nerve fiber layer atrophy as relevant feature for diffuse unilateral subacute neuroretinitis (DUSN): case series. Arquivos brasileiros de oftalmologia. 73(2): 182-185

37. Vianna RN, Onofre G, Ecard V, Muralha L, Muralha A, de Amorim Garcia CA (2006) Indocyanine green angiography in diffuse unilateral subacute neuroretinitis. Eye. 20(9):1113-6

38. Stokkermans TJ (1999) Diffuse unilateral subacute neuroretinitis. Optometry and vision science : official publication of the American Academy of Optometry. 76(7):444-454

39. Martidis A, Greenberg PB, Rogers AH, Velazquez-Estades LJ, Baumal CR (2002) Multifocal electroretinography response after laser photocoagulation of a subretinal nematode. American journal of ophthalmology. 133(3):417419

40. Garcia CA, Gomes AH, Vianna RN, Souza Filho JP, Garcia Filho CA, Orefice F (2005) Late-stage diffuse unilateral subacute neuroretinitis: photocoagulation of the worm does not improve the visual acuity of affected patients. International ophthalmology. 26(1-2):39-42

41. Cialdini AP, de Souza EC, Avila MP. The first South American case of diffuse unilateral subacute neuroretinitis caused by a large nematode. Archives of ophthalmology (Chicago, III : 1960). 1999;117(10):1431-1432.

42. Venkatesan P (1998) Albendazole. The Journal of antimicrobial chemotherapy. 41(2):145-147

43. Spaide RF, Koizumi H, Pozzoni MC (2008) Enhanced depth imaging spectraldomain optical coherence tomography. American journal of ophthalmology. 146(4):496-500

44. Gomes AH, Garcia CA, Segundo Pde S, Garcia Filho CA, Garcia AC (2009) Optic coherence tomography in a patient with diffuse unilateral subacute neuroretinitis. Arquivos brasileiros de oftalmologia. 72(2):185-188

45. Kalevar A, Jumper JM (2017) Optical coherence tomography angiography of diffuse unilateral subacute neuroretinitis. American journal of ophthalmology case reports. 7:91-94

46. Barisani-Asenbauer T, Maca SM, Hauff W, Kaminski SL, Domanovits H, Theyer I et al (2001) Treatment of ocular toxocariasis with albendazole. Journal of ocular pharmacology and therapeutics : the official journal of the Association for Ocular Pharmacology and Therapeutics. 17(3):287-294

47. McDonald HR (2003) Diagnostic and therapeutic challenges: diffuse unilateral subacute neuroretinitis. Retina. 23:92-96

48. Venkatesh P, Sarkar S, Garg S (2005) Diffuse unilateral subacute neuroretinitis: report of a case from the Indian subcontinent and the importance of immediate photocoagulation. International ophthalmology. 26(6):251-254
49. Casella AM, Farah ME, Belfort R Jr (1998) Antihelminthic drugs in diffuse unilateral subacute neuroretinitis. American journal of ophthalmology. 125(1):109-111

50. Gass JD, Callanan DG, Bowman CB. Oral therapy in diffuse unilateral subacute neuroretinitis. Archives of ophthalmology (Chicago, III : 1960). 1992;110(5):675-680.

51. Casella AMB, Farah ME, Bonomo PB, Souza EC (1994) Neurorretinite subaguda unilateral difusa: descryção de três casos no Estado do Pará, Brasil. Arq Bras Oftalmol 57:77-79

52. de Souza EC, da Cunha SL (1992) Neurorretinite subaguda difusa no Brasil: encontro da larva subretiniana. Arq Bras Oftalmol 55:251-254

53. Maizels RM, Yazdaubakhsh M (2003) Immune regulatory by helminth parasites: cellular and molecular mechanisms. Nature Rev 3:733-744

54. Rizzitelli G, Scarabelli G, Veraldi S (1997) Albendazole: a new therapeutic regimen in cutaneous larva migrans. International journal of dermatology. 36(9):700-703

55. Singhi P, Dayal D, Khandelwal N (2003) One week versus four weeks of albendazole therapy for neurocysticercosis in children: a randomized, placebo-controlled double blind trial. The Pediatric infectious disease journal. 22(3):268-272

\section{Publisher's Note}

Springer Nature remains neutral with regard to jurisdictional claims in published maps and institutional affiliations.

\section{Submit your manuscript to a SpringerOpen ${ }^{\circ}$ journal and benefit from:}

- Convenient online submission

- Rigorous peer review

- Open access: articles freely available online

High visibility within the field

- Retaining the copyright to your article

Submit your next manuscript at $>$ springeropen.com 